\title{
A PERMANÊNCIA NA CARREIRA DO PROFESSOR DE CIÊNCIAS: UMA LEITURA BASEADA EM CHARLOT
}

\author{
Marcela Yaemi Ogo* \\ Carlos Eduardo Laburú**
}

RESUMO: O ciclo de vida profissional do professor já foi delimitado por autores como Huberman. Coloca-se à literatura a necessidade da realização de pesquisas que tragam novas perspectivas sobre a carreira desse profissional e, em específico, do professor de Ciências. Ao compararmos os obstáculos e as satisfações encontradas na carreira encontramos nítidas diferenças entre os profissionais docentes, o que justifica a preocupação de focar atenção nos aspectos que mantêm o docente de Ciências na carreira, apesar dos inúmeros desafios por ele encontrados. O referencial teórico utilizado baseia-se em uma leitura das relações com o saber de Charlot, a fim de buscar um novo olhar para esse problema. Também empregamos o referencial de ciclo de vida de professores de Huberman para obter a história de vida dos professores, definir o professorado a ser analisado e construir um instrumento de entrevista. A amostra selecionada de professores encontra-se na terceira fase descrita por Huberman, de Diversificação ou Questionamento. O referencial de Charlot servirá para analisar essa fase da carreira docente para que compreendamos a razão ou razões que fazem com que o professor de Ciências persista na carreira. Palavras-chave: Charlot; Huberman; Ciclo de Vida Profissional do Professor de Ciências.

\section{THE PERMANENCE IN THE CAREER AS A SCIENCE TEACHER:}

\section{A CHARLOT BASED READING}

ABSTRACT: The life cycle of the teacher has been defined by authors such as Huberman. The literature is, thus, entrusted with the need for conducting research to bring new perspectives on the career of a professional and in particular the science teacher. While comparing the obstacles and the satisfaction found along the career, one detects clear differences among professional teachers, hence the concern to focus attention on the aspects that make the teacher of Science uphold their career, despite the many challenges they encounter. The theoretical framework is based on the interpretation of the relations with the knowledge by Charlot in order to get a new look at this problem. We also use the reference of the life cycle of teachers of Huberman to get the life story of the teachers, the teachers set to be analyzed and build an instrument for interview. The selected sample of teachers is the third stage described by Huberman, Diversification or Questioning. The Charlot's referential serve to analyze this phase of the teaching profession to understand the reason or reasons that make the Science teacher persist in his career.

Keywords: Charlot; Huberman; Science Teacher's Professional Cycle of Life.

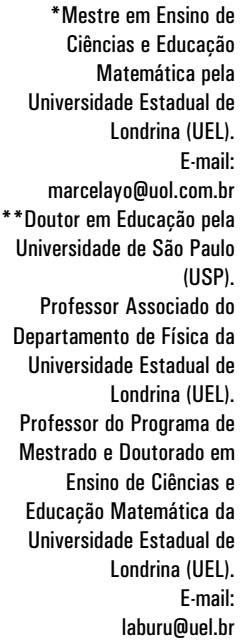

* Mestre em Ensino de Ciências e Educação Matemática pela Universidade Estadual de Londrina (UEL).

E-mail:

marcelayo@uol.com.br

* *Doutor em Educação pela Universidade de São Paulo (USP).

Professor Associado do Departamento de Física da Universidade Estadual de Londrina (UEL).

Professor do Programa de Mestrado e Doutorado em

Ensino de Ciências e Educação Matemática da Universidade Estadual de Londrina (UEL).

E-mail:

laburu@uel.br 


\section{INTRODUÇÃO}

O estudo da história de vida dos professores permite a colocação desses profissionais como tema central das problemáticas de investigação também no Ensino de Ciências. As investigações acerca do ciclo de vida dos professores (HUBERMAN, 1995) permitem o levantamento a respeito de questões biográficas dos docentes, ampliando o estudo sobre sua formação. Neste trabalho, o ciclo de vida profissional parte das pesquisas sobre a história de vida docente, sendo esta história um instrumento valioso para extrair informação sobre a carreira dos professores.

A fim de se compreender o ciclo de vida docente fazemos uso de um paralelismo com as relações do saber descritas por Bernard Charlot (2000). Seu trabalho trata das relações com o saber dos estudantes e da relação destes com o fracasso escolar. Porém, aqui voltamos o referencial analítico do autor para estudar as relações com o saber profissional dos professores de Ciências, como fizeram Laburú et al (2007), Mamprim et al (2008), Assis et al (2009) e Salvadego \& Laburú (2009) com a finalidade de entender o fracasso de se empregar atividades experimentais no ensino das diferentes Ciências Naturais. Com o mencionado referencial, propomos um novo olhar para compreender as razões que levam o professor de Ciências a persistir na carreira.

A leitura baseada nas relações com o saber profissional dos professores pretende ser uma perspectiva teórica auxiliadora para explicar como ocorre a construção da identidade profissional do professor de Ciências ao longo de muitos anos de profissão. Como resultado dessa construção é possível responder o seguinte problema: elucidar as relações que o professor mantém com a sua carreira, os alunos, o conhecimento da disciplina que ministra, a escola e consigo mesmo e, assim justificar sua permanência na carreira docente.

Para responder ao problema central colocado acima, fizemos uso da descrição de Michaël Huberman (1995) referente às diferentes fases da carreira docente e de sua ideia de perscrutar a história de vida docente. Após a obtenção dessa história de vida aplicamos uma leitura das relações com o saber de Charlot (2000), a fim de encontrarmos os motivos que levam o professor a se manter por um extenso período de tempo na profissão.

Durante as décadas de 1970 e 1980, Huberman destacou-se por tratar o ciclo de vida profissional dos professores. O autor encontrou características semelhantes entre os professores em diferentes fases da carreira e as agrupou em categorias. Aproveitando-nos desse trabalho, vimos a relevância de uma investigação que comportasse um estudo da terceira fase delineada nesse ciclo profissional, aplicando-a nos professores de Ciências e justificando-a na metodologia.

No entanto, ao servirmo-nos de uma leitura do trabalho de Charlot como ferramenta analítica para explicar a terceira fase escolhida, descrita por Huberman no ciclo de vida profissional dos professores de Ciências, nos foi possível mostrar quais fatores influenciam a permanência desse profissional na 
carreira segundo uma ótica das relações com o saber. Por meio da proposta de Charlot, baseada nas relações dos indivíduos com o saber e que pode de fato ter uma relação com o Eu, com o Outro e com o Mundo, apresentamos uma diferente perspectiva ao examinarmos os motivos pelos quais o professor insista em permanecer na carreira docente.

\section{REFERENCIAIS TEÓRICOS}

\section{Formação de professores de Ciências}

O debate sobre a formação de professores vem crescendo nas últimas décadas. A preocupação com a qualidade do ensino enfatizou os estudos de formação docente. No Plano Nacional de Educação consta que a formação do professorado depende da formação inicial, das condições de trabalho, do salário, da carreira e da formação continuada (BRASIL, 2001). É preciso levar em conta que o aperfeiçoamento docente é contínuo e pessoal. Durante a trajetória de vida, o docente constrói e reconstrói os conhecimentos sobre sua profissão de acordo com suas experiências e sua vivência.

A profissão docente passou, e ainda passa, por um processo de desvalorização e desprestígio. Por outro lado, esses profissionais estão em um processo de profissionalização, que possibilita reverter tal situação. A formação de professores tem desempenhado importante papel nesse sentido. Ela depende, além de cursos de aperfeiçoamento, reciclagem e de formação permanente de um processo de reflexão crítica sobre sua própria prática.

Tem-se percebido um distanciamento entre as pesquisas realizadas na área de formação de professores e o ensino de Ciências (CARVALHO e GILPÉREZ, 2006). O ensino é concebido como algo simples, exigindo somente ter competência sobre a matéria, alguma prática e pouco conhecimento pedagógico. Assim, é propagada a ideia de formação do professor como mera transmissão de conhecimentos, sendo mantida pouca familiarização dos professores de Ensino Fundamental e Médio com as pesquisas na área de ensino de Ciências. A união entre prática cotidiana de ensino e a pesquisa didática é possível a partir de uma concepção de ação/pesquisa em que o professor deve ser capaz de intervir na sua própria prática. Além disso, atualmente os professores têm que estar preparados para situações não acadêmicas com seus alunos. A violência e a agressividade vêm atravessando os muros da escola e se instalando nas salas de aula. É fundamental que o professor seja capaz de perceber, refletir e atuar nesses momentos.

É possível dizer que há um encanto na docência, na sala de aula, nos alunos, na Pedagogia e um investimento em um futuro incerto. Por muitos anos, o professor na sua prática recebeu diversos adjetivos: abnegação, sacrifício, bondade, paciência e sabedoria. Mas hoje se exige desse mesmo docente: profissionalização, autonomia e revalorização. Ainda assim, as reais deficiências dos pro- 
fessores no exercício profissional se encontram ocultas nas deficiências da instituição escolar, do currículo, das metodologias e dos recursos didáticos. Adicionase a isto a desqualificação profissional sofrida pela categoria de professores, os salários, a diminuição do status social e as precárias condições de trabalho (BRASIL, 2002). Apesar de todas as exigências e desgastes da profissão docente, muitos continuam educando. Para Freire (1997, p. 8), a docência:

É uma tarefa que requer de quem com ela se compromete um gosto especial de querer bem não só aos outros, mas ao próprio processo que ela implica. É impossível ensinar sem essa coragem de querer bem, sem a valentia dos que insistem mil vezes antes de uma desistência.

Acreditamos que ao estudar a história de vida, o desenvolvimento profissional e principalmente o ciclo de vida dos professores seja possível contribuir para os estudos acerca da permanência e resistência dos professores.

\section{História de vida dos professores}

A profissão docente destaca-se, entre outras características, pelas relações interpessoais. Muitos estudos no século XX detiveram-se nas dimensões racionais na formação de professores. Após um período sem a existência de uma preocupação com os professores, na década de 1980 surgiram estudos com foco na vida e na identidade do professor (GONÇALVES, 1995; STANO, 2001; TARDIF, 2002; PASSOS, 2008). Nesses estudos houve a preocupação com a crise de identidade pela qual esses profissionais passam. A construção dessa identidade é um processo que depende da história pessoal e profissional do indivíduo e sobre o qual o professor constrói uma história de vida.

As histórias de vida dos professores podem gerar reflexões e práticas sobre a docência. Nos últimos trinta anos, os estudos sobre as histórias dos professores vêm recebendo destaque e promovendo algumas mudanças. Para Nóvoa (1995, p. 25), a "formação não se constrói por acumulação (de cursos, de conhecimentos ou de técnicas), mas sim através de um trabalho de reflexividade crítica sobre as práticas e de (re)construção permanente de uma identidade pessoal." Segundo García (1997), convém prestar atenção especial ao conceito de desenvolvimento profissional dos professores, por ser aquele que melhor se adapta à concepção atual do professor como profissional do ensino. A noção de desenvolvimento tem uma conotação de evolução e de continuidade que nos parece superar a tradicional justaposição entre a formação inicial e o aperfeiçoamento dos professores. O desenvolvimento profissional depende das experiências do professor dentro e fora da sala de aula, além da formação inicial e continuada e das interações com o que e com quem o cerca.

Huberman (1995), por sua vez, trabalha com o ciclo de vida docente, dividindo-o em fases. Embora se deva admitir que os aspectos durante a carrei- 
ra variem de um indivíduo para o outro, foi encontrado por ele que em geral, existem características que são comuns à maioria dos professores. Os estudos sobre o ciclo de vida profissional dos professores mostram que existem diferentes fases ou etapas, próprias aos indivíduos. Deve-se considerar que uma nova fase pressupõe alteração das características da anterior e a assunção de novas (GONÇALVES, 1995).

Huberman realizou o estudo das etapas da carreira docente, especificamente com professores do nível secundário que não tinham responsabilidades em cargos administrativos. O autor divide o ciclo nas seguintes fases: Entrada, Estabilização, Diversificação, Questionamento, Serenidade e Distanciamento afetivo, Conservantismo e Lamentações e Desinvestimento.

A fase de Entrada (1-3 anos de carreira) é um estágio de sobrevivência, exploração e descoberta. Há preocupação consigo; um distanciamento entre os ideais e a realidade na sala de aula; surgem dificuldades com os alunos e com o material didático. É um período de experimentação, no qual o professor adquire maior responsabilidade e passa a sentir-se parte de um corpo profissional.

A Estabilização (4-6 anos de carreira) é um momento em que há um comprometimento definitivo com a profissão. O professor passa a tomar mais responsabilidades; adquire uma identidade profissional, pois renuncia a outras identidades, fazendo escolhas. Nessa fase ocorre maior uso de recursos técnicos e o professor passa a sentir confiança, apresentando um estilo próprio de ensino.

No período de Diversificação (7-25 anos de carreira) há uma maior diversificação do material didático, dos modos de avaliação, na forma de agrupar os alunos e na sequência das aulas. É uma fase ativista, de maior comprometimento. Os professores que se encontram nesta fase são descritos como os mais motivados, dinâmicos e empenhados nas equipes pedagógicas. É um período de busca de ambição pessoal, quando o profissional demonstra mais autoridade, responsabilidade e prestígio, buscando até mesmo postos administrativos na instituição.

Os professores que se encontram na fase de Questionamento (7-25 anos de carreira) põe-se em questão, demonstrando sensação de rotina. O professor faz um balanço da vida profissional e passa a questionar se deve seguir ou não outras carreiras durante o tempo em que ainda é possível. Este professor sofre influências externas, da instituição, do contexto político e/ou econômico e da vida pessoal.

A fase de Serenidade e Distanciamento afetivo (25-35 anos de carreira) ocorre após uma sucessão de fases de questionamento, onde o indivíduo pode arrepender-se do ativismo ou tornar-se uma pessoa com serenidade. O nível de ambição do professor cai, ele reduz o investimento, mas a confiança e a serenidade aumentam. Há um distanciamento entre aluno e professor.

Os professores em fase de Conservantismo e Lamentações (25-35 anos de carreira) se caracterizam por queixas sobre os alunos, alegando que são menos disciplinados, menos motivados, "decadentes". Criticam a política educacional, 
alegando que esta é confusa, sem orientação, clara e frouxa; e também os colegas mais jovens, considerando-os menos sérios e pouco empenhados. No exercício da profissão há maior rigidez, prudência e uma resistência às inovações. $\mathrm{E}$ tendem à nostalgia.

A carreira culmina em uma fase chamada Desinvestimento (35-40 anos de carreira), que é um período comum a todos os professores. $\mathrm{O}$ sujeito apresenta uma postura positiva, com libertação progressiva e sem lamentações. Segundo Huberman (1995), os outros docentes, que não puderam chegar longe quanto às ambições desinvestem já no meio da carreira, devido a desilusões com os resultados do trabalho, ou das reformas, canalizando para outros lados suas energias.

\section{A OBRA DE CHARLOT}

O trabalho de Charlot aborda o dito "fracasso escolar", analisando as relações com o saber dos alunos. A expressão "fracasso escolar" é uma maneira de verbalizar a experiência, a vivência e a prática, tendo em vista a reprovação e a não aquisição de certos conhecimentos ou competências. Segundo Charlot, não existe o "fracasso escolar", mas alunos que não conseguem acompanhar o ensino que lhes é ofertado. Charlot afirma que esse fracasso não é apenas uma questão de diferença social, mas decorre de situações vivenciadas pelos alunos. A teoria que aborda o fracasso escolar como tendo origem na realidade social trata de fato em compreender a questão sob a óptica das faltas, mostrando uma leitura negativa do que precisaria estar contemplada para haver sucesso.

Segundo Charlot, o sujeito é um ser portado de desejos e movido por eles, que nasce e cresce em uma família, ocupa uma posição em um espaço social, inscrito em relações sociais. Trata-se de um ser único, que tem uma história, é capaz de interpretar o mundo e dar um sentido a ela e às suas relações com os outros. Esse autor afirma que o saber é uma informação da qual o sujeito se apropria e que pode ser disponibilizada a outra pessoa. Para ele não há saber que não esteja inscrito em relações de saber. A ideia de saber refere-se a um sujeito, à sua atividade, à relação desse sujeito consigo mesmo, com os outros e com o mundo, o que implica em uma forma de atividade, uma relação com a linguagem e uma relação com o tempo.

Dependendo das relações mantidas com o saber há ou não mobilização. Charlot (2000, p. 55) prefere o termo "mobilizar-se" ao termo "motivação": "A mobilização implica mobilizar-se ('de dentro'), enquanto motivação enfatiza o fato de que se é motivado por alguém ou por algo ('de fora'). Assim, o aluno mobiliza-se ao realizar uma atividade, investindo nela, quando a mesma é colocada em movimento por móbeis que remetem a um desejo, um sentido, um valor. Aprender pode significar apropriar-se do saber, mas depende de objetos empíricos, ocorre em determinados espaços e deve vir de pessoas que já aprenderam. No aprender há um Eu e ao aprender o saber assume a forma de objeto 
e é intermediado pela linguagem. Toda relação com o saber é também uma relação com o outro, mas vai além. O outro pode não ser representado apenas por algo ou alguém fisicamente presente. Há casos em que existe o "fantasma de um outro", que cada um leva consigo (CHARLOT, 2000).

\section{Uma leitura das relações com o saber de Charlot}

Defendemos que a permanência do professor na carreira está relacionada às relações com o saber profissional. As relações com o Eu, o Outro e o Mundo são indissociáveis e podem esclarecer onde se encontram as relações com o saber profissional de um docente e que justificam sua permanência na carreira. Então, uma relação com o saber profissional implica em relações com o Eu, o Outro e o Mundo.

A relação do sujeito com o Mundo apresenta uma dimensão epistêmica no que se refere à forma de apropriação de um saber que não se possui e, no caso específico do nosso trabalho, esta relação se reduz a relação do professor com os conhecimentos exigidos pela profissão (LABURÚ, 2007). A relação com o Mundo tem a ver, então, com o conhecimento pedagógico que o professor cultiva em relação às Ciências, de como aprendê-la e, também, de como ensiná-la, podendo influenciar inclusive no uso ou não por ele de atividades experimentais (op. cit.). Portanto, os aspectos que se referem à relação com o conhecimento profissional do professor de Ciências, tanto pedagógica quanto científica, serão aqui compreendidos como uma relação com o Mundo.

A relação com o Eu faz referência à história de vida do profissional, a sua perspectiva de vida, às expectativas, à imagem que quer ter e passar de si e que influenciam na decisão da escolha da profissão. Estabelecer relações com o Eu é manter situações idealizadas para si, por si mesmo ou por outros (pais, amigos), fantasiar com base em situações e significações a que o sujeito se apega. A realização profissional do indivíduo tem a ver com a concretização do que ele projetou para si e está relacionada com o que faz, produz e contribui para a sociedade. Dessa forma, ao analisar a história do professor, suas referências, concepção de vida e expectativas, é possível perceber qual o grau de comprometimento e engajamento com seu trabalho.

Por último, a relação com o saber profissional mantém uma relação com o Outro. O convívio do professor com seus colegas de profissão, com os alunos e seus pais, com os membros da direção do colégio ou a equipe pedagógica que lhe atribui missões ou pressiona a agir de determinada maneira. Nesse último caso, nota-se que o outro pode ser aquele que não está fisicamente presente, é o "fantasma do outro" e, nesse sentido, de forma semelhante, é ingressar na comunidade virtual daqueles que detêm as mesmas capacidades, ou de um imaginário que mantém um olhar de regulação sobre mim (CHARLOT, 2000, p. 72-73). Quando a assunção de papéis comporta uma imitação de um determinado personagem ou de um ideal e de outro, por admiração, respeito, considera- 
ção, ou seja, quando há tentativa de imitar em razão da influência de outrem, que acaba resultando "em um eu como se fosse ele", entendemos, de forma semelhante, uma relação com o Outro. Esse tipo específico de relação, baseada em um mecanismo de assunção de papéis, concretiza-se em um ato consciente ou inconsciente de réplica a conduta de "alguém". Assim, por exemplo, um professor poderia se espelhar em um imaginário de "bom professor" e desempenhar tal papel.

As três relações anteriores não podem ser analisadas separadamente, todavia, pois ao se estabelecer uma ligação com si próprio, o sujeito também mantém uma relação com o Mundo, e ambas dependem da relação com o Outro.

\section{METODOLOGIA}

Ao adequar sua obra para os interesses desta investigação, a abordagem de Charlot (2000) serviu de ferramenta analítica para o tratamento dos dados, e que se encontram relacionados à terceira fase do ciclo de vida profissional dos professores. Por sua vez, a obra de Huberman (1995) foi essencial tanto para a seleção e identificação prévias dos professores participantes da amostra na fase de interesse, como para a elaboração da entrevista com o objetivo de buscar a descrição da história de vida de cada profissional.

A coleta de dados baseada em entrevistas semiestruturadas (BOGDAN $\&$ BIKLEN, 1994), gravadas em áudio, nos períodos de hora-atividade e descanso dos professores e posteriormente transcritas para serem analisadas.

Como sujeitos da pesquisa foram escolhidos professores de Ciências de escolas públicas do norte do Paraná, entre 10 e 20 anos de carreira docente. Esse período de carreira docente foi selecionado porque se refere às fases ou de Diversificação ou de Questionamento que se encontram mais adequadas às condições brasileiras. Segundo os estudos realizados na Europa, Huberman (1995) situa essa fase entre os sete os 25 anos de carreira docente. Seus trabalhos basearam-se em um ciclo profissional de 40 anos adequado aos países europeus. No Brasil, entretanto, poucos professores chegam a esse tempo de experiência profissional. Por isso, ajustamos o ciclo profissional de Huberman para a realidade brasileira que apresenta um período médio de 30 anos. Partindo, então, de um ciclo de 30 anos, buscamos situar as suas fases nesse período de tempo. O critério para essa decisão foi o seguinte: como as fases de Diversificação e Questionamento situam-se no meio da carreira, a transposição para o ciclo de 30 anos brasileiro leva a uma média de 15 anos. Então, escolhemos cinco anos antes e cinco anos depois, ou seja, o intervalo que vai dos 10 aos 20 anos da carreira.

Como o nosso problema de pesquisa refere-se à permanência do professor na carreira, escolhemos a terceira fase descrita por Huberman. As fases de Entrada e Estabilização referem-se aos primeiros anos de carreira docente e são comuns a todos os docentes. Nessas fases, o profissional passa por um período 
de experiência e reconhecimento da sua identidade, mas ainda não é possível prever sua permanência ou desistência da carreira. Nos estágios de Serenidade ou Distanciamento afetivo e de Conservantismo e Lamentações, o sujeito tende a reduzir seu investimento na carreira ou queixar-se, mas tende a finalizar a carreira alcançando a fase de Desinvestimento. Por este motivo focamos nosso trabalho nas Fases de Questionamento ou Diversificação, em que o profissional encontra-se altamente motivado ou em um momento de desgaste, mas já está, no caso brasileiro, em meados de sua carreira profissional. Como é nessa fase, segundo Huberman, que o professor tende a se questionar se deve ou não mudar de carreira ou ser considerado muito motivado e dinâmico, escolhemo-la para procurar os motivos que mantêm os docentes na carreira.

As perguntas feitas aos professores basearam-se nas características descritas por Huberman (1995) sobre cada uma das fases do ciclo de vida profissional. Como o roteiro de entrevista foi baseado em seu trabalho, os questionamentos tiveram como objetivo descobrir se os entrevistados realmente apresentavam características referentes à fase de Diversificação ou de Questionamento e não dos estágios anteriores ou subsequentes, determinando, assim, a seleção da amostra. Dessa forma, foi mais contundente encontrar professores que já tinham passado pela fase de Estabilização, mas que ainda não haviam chegado à fase de Conservantismo ou de Serenidade.

Como dissemos, a leitura das relações com o saber de Charlot foi essencial na análise e interpretação da história de vida que mostra toda a trajetória profissional do docente. A análise dos dados está baseada nas categorias das relações com o Eu, com o Outro e com o Mundo descritas na seção teórica. As falas dos entrevistados estão apresentadas em itálico e negrito. Dois dos representantes da amostra pesquisada por Ogo (2010) demonstram no presente trabalho a aplicação do referencial teórico. O roteiro de questões, as transcrições completas das entrevistas aqui citadas e de outras que também corroboram com os resultados encontrados podem ser encontradas na íntegra em Ogo (2010).

\section{Análise e interpretação dos dados}

\section{Professor 1}

O Professor 1 atua há 19 anos na atividade docente. É licenciado em Biologia, tem especialização em Biologia Aplicada à Saúde e ministra aulas de Ciências. Relata que prestou vestibular para esse curso devido às condições financeiras da família, pois o mesmo estava disponível em sua cidade. Ele informou que no início da sua carreira possuía uma relação de desejo com outra área de atuação alternativa à Biologia e que esta não era prioritária, o que é sugerido na seguinte afirmação: "Eu tinha uma outra opção que era faz̧er Linguas, só que aí inclusive eu tive uma influência, uma professora que eu tinha no $2^{\circ}$ gran [...] que aconselhou que Letras não era legal.” Essa relação também não se encontrava na licenciatura, pois 
ao iniciar a carreira docente, percebeu que a profissão de biólogo era desvalorizada. "[...] é muito mais expressivo você fazer Agronomia, você fazer Veterinária, fazer Medicina, Odonto, porque o curso de biólogo [...] a gente optou mais por dar aula." Vê-se, igualmente, que sua escolha em lecionar a disciplina de Ciências ocorreu por conveniência, conforme mostra a seguinte afirmação: "eu fui assim analisando essas situações de mercado, de colocação de mercado e acabei ficando com Ciências apesar de ter podido pegar Biologia.”. Essa colocação evidencia que ele preferia lecionar Biologia, mas sua escolha por aulas de Ciências ocorreu devido à maior disponibilidade de aulas. É possível verificar que a relação com o Eu se faz presente na necessidade de buscar maior quantidade de aulas, o que o conduz a se afastar da prática de sua licenciatura de formação.

As falas anteriores indicam que a relação com o Eu de necessidade econômica do professor é evidenciada pela sua opção em escolher maior quantidade de aulas de Ciências. Sua relação com o Mundo se encontrava inicialmente no estudo de Línguas, o que foi abortado devido à influência de uma professora que o desaconselhou a seguir essa opção, e também devido à restrição econômica que o obrigava a frequentar o curso de Biologia somente na cidade em que morava. Sua relação com o Mundo mantém um vínculo fraco com a licenciatura de Biologia, o que é evidenciado pelo seu comentário a respeito das outras profissões. A necessidade de reconhecimento profissional é característica da relação com Eu, o que se vê na indicação da desvalorização do biólogo comparado a outros profissionais por ele mencionados, como o veterinário e o dentista.

O professor mostrou-se frustrado com algumas condições que encontra atualmente, principalmente devido às políticas pedagógicas. "[...] Existem muitas políticas governamentais que estão jogando o aluno pra dentro da escola, mas simplesmente jogando, só pro aluno ficar trancado lá dentro. [...] eu fico frustrado." Devido a sua relação com o Eu e o Mundo estar fora da licenciatura de Biologia e Ciências vemos o discurso da queixa sendo colocado para justificar seu descontentamento, responsabilizando as políticas governamentais pela sua frustração. Inclusive, essa postura de depositar num Outro imaginário (políticas governamentais) sua queixa vai de encontro com a afirmação de gostar de dar aulas. "Tive problemas no preenchimento de papéis. Por exemplo, corrigir provas [...]" "[...] não tem muito resultado nessa parte burocrática.” Apesar de aparentemente demonstrar preocupação com os alunos, o que poderia representar uma relação com o Outro e assim justificar uma postura favorável para com a profissão, continua havendo um discurso de queixa, agora depositado em um Outro burocrático para legitimá-las.

Fica claro que as relações com o Eu, com o Outro e com o Mundo deste professor não estão na licenciatura. De fato, momentos da entrevista apontam que o seu desejo de constituir família e uma decorrente segurança econômica são fatores que o mantém na carreira de professor. Essas exclusivas relações com o Eu não surgem como consequência de um desejado trabalho de docência, pelo contrário, elas são prioritárias ao tipo de trabalho que vem sendo exercido, sendo este uma mera fonte segura de obtenção de renda para satisfazer 
aqueles desejos. Inspirados em Pichon-Rivière (2000) percebemos sua resignação em não superar esse estado de coisas, mudando de profissão, fica também configurada pela sua ansiedade de ataque. Em outras palavras, o sentir-se atacado surge do medo ou da insegurança da mudança, do medo da falha, de sair de um estereótipo anterior que é mantido por inércia e de não estar instrumentado o suficiente para se defender dos perigos que se acredita incluídos no novo campo ou situação diferente. Em razão das suas relações com o Eu específicas apontadas e que envolveriam a superação da ansiedade de ataque depositada num Outro ilusório e que se vê identificado na origem singela e nas possibilidades externas não favoráveis ("[...] minha história de vida é humilde [...] Eu não tive chance de melhorar.'), o sujeito projeta no discurso da falta (ser humilde) a justificativa para sua situação profissional.

Ele afirmou que não conseguiria continuar na carreira docente: "[...] tô chegando a uma conclusão, que eu vou ter que desenvolver uma outra atividade [...] tentando ver se eu consigo montar alguma coisa, algum negócio, pra poder tocar.” O professor, ao ser questionado se a nova atividade estaria relacionada ao ensino, respondeu afirmativamente, pois achava adequado aproveitar os conhecimentos aprendidos. “É relacionado ao ensino [...] com certeza não vou conseguir finalizar a minha carreira como professor [...] Eu vou ter que terminar a carreira uns 10 anos antes."

Por estas falas está patente a demonstração de descontentamento do professor a respeito de sua profissão. Suas declarações, de que está na metade da carreira e que precisa melhorar não se referem à docência, mas, sim, a algo fora desta, como se pode ver: "em 95, por exemplo, na questão dos computadores, [...] queria montar um laboratório de informática. E (a diretora) me convidou então para gerenciar a construção desse laboratório de informática [...] eu sai de sala de aula, eu já trabalhei como técnico em outras áreas, do Estado, né?" Aqui se nota que a relação com o Mundo deste professor está afastada da sala de aula ("[...] eu saí de sala de aula"). Ela se encontra na informática, no trabalho técnico, na atividade profissional mais empreendedora, ligada ao comércio e informática.

O discurso da queixa do Professor 1 em vários momentos da entrevista garante o argumento de que suas relações com Eu, o Outro e o Mundo não se voltam para a docência. Viu-se que a sua relação com o Eu está fundamentalmente em resolver seus problemas econômicos e de sustento de sua família. Estas não passam pela profissão exercida, havendo uma ausência de comprometimento com a mesma.

A permanência na carreira durante 19 anos só se justifica a partir de uma relação com o Eu de necessidade em se manter um salário para sua manutenção e de seus familiares. Com isso, o fator econômico é o que o mantém na carreira até o momento, sendo um fator que não o faz finalizá-la, posto que suas relações com o Eu e o Mundo estão voltadas para atividades em que o magistério não se vê contemplado.

O Professor 1 apresenta características da fase de Questionamento na medida em que mantém o discurso da queixa, da insatisfação com as condições 
de seu trabalho. Ele põe em questão a si mesmo e suas escolhas, sendo que os fatores que influenciam seu questionamento são as condições pessoais e o contexto político, citados por ele. Mas é através da perscrutação oportunizada pelas relações com o Eu, o Outro e o Mundo, refinando a análise, que se permite ver que por detrás dessa fase na qual existe um simples questionamento, que as relações com o saber profissional desse professor estão em outro lugar e não no magistério, fazendo com que sua permanência na carreira se dê por relações de necessidade econômica.

\section{Professora 2}

A Professora 2 é formada em Ciências Biológicas e atua na atividade docente há 16 anos. $\mathrm{Na}$ época da entrevista, a docente estava participando do PDE (Plano de Desenvolvimento da Educação). A professora relatou que depois de iniciar o curso de Ciências Biológicas ainda prestou vestibular para o curso de Farmácia, no entanto, recuou: "[...] Eu tentei pedir transferência do curso de Biologia no primeiro periodo, ai depois eu desisti [...] eu achei que en me identifiquei no curso de Biologia e não me identificaria de Farmácia." Ela relatou que teve afinidade com a disciplina de Ciências desde o Ensino Fundamental: "Eu sempre gostei muito de Ciências e Matemática. E da matéria de Biologia no Ensino Médio. Tanto Ciências e Matemática da $5^{a}$ a $8^{a}$ no Ensino Fundamental, quanto com Biologia no Ensino Médio." Assim, é possível verificar uma relação com o Eu em que a entrevistada mostra uma vocação para a docência.

Sua opção por licenciatura ocorreu por influência de um professor do Ensino Médio: "[...] Eu tinha um professor de Biologia que eu amava, adorava ele. [...] e eu me identifiquei com ele. Ele serviu como modelo." Neste caso, é possível verificar uma indissociável relação entre o Eu, com o Outro e com o Mundo. A relação de identificação consigo mesma ("eu amava, adorava"), simultaneamente estabelece uma relação com o mundo do conhecimento de Biologia e, por sua vez, está na dependência da relação com o outro (professor), como confirmam as próximas falas.

Quando questionada sobre os motivos que a levaram a lecionar a disciplina de Ciências, ela demonstrou que preferia Biologia: "Eu prefiro Biologia. [...] quando eu comecei a trabalhar, eu comecei a trabalhar com Biologia e Ciências. [...] eu trabaIhava com Matemática da $5^{a}$ a $8^{a}$ [... ]" A professora ao se graduar, logo começou a ministrar aulas de Biologia em uma escola particular. Em seguida, começou dar aulas de Matemática no Estado e no ano seguinte ministrou as duas disciplinas: [...] sobravam aulas de Matemática. [...] Então eu pegava o que eles não queriam, eu pegava Matemática." Após concurso público, a professora passou a lecionar Ciências e Biologia, atuando dessa forma até hoje. Embora inicialmente na entrevista houvesse a impressão de que a relação com o Mundo da entrevistada não estivesse na docência e nem em Ciências, as demais falas da professora puderam dissipar as suspeitas. Apesar de ter tentado mudar de curso na graduação, ela recuou e acabou situando-se no curso de Ciências Biológicas. E quando decidiu lecionar 
Matemática, sua decisão foi tomada por conveniência, já que conseguiria maior número de aulas do que ministrando aulas de Biologia ou Ciências.

A professora afirmou que pretende estudar e capacitar-se mais: "[...] Eu to fazendo o PDE que é dois anos, o que pro Estado do Paraná equivale a um mestrado. Mas eu tenho interesse em fazer um mestrado mais pra frente. E na área de Educação", "[...] E mesmo depois de todas as elevações, eu continuei me capacitando. [...]” Aqui, verificamos uma relação Eu/Mundo da professora com sua profissão devido ao interesse da entrevistada em procurar outro curso, além daquele que participava na época da entrevista, como um possível mestrado, evidenciando o desejo em permanecer na docência e se especializar, já que pretende procurar um curso de Pós-Graduação na área da Educação.

Quando questionada sobre a imagem que tem de si mesma como professora (relação com o Eu), a docente fala a respeito do conceito que os alunos expressam sobre ela e seu relacionamento com eles: "Bem, meus alunos falam que eu tenho uma paciência de Jó. [...] Eu faço aula prática. Pego e levo para o laboratório, pra ver alguma coisa. Saio na cidade, e eles gostam disso. [...] Ah, não tá bem? Por que que não tá bem? [...] De repente eu posso ajudar e ai ele melhora. [...] Conteúdo eu acho que eu passo muito bem pra ele [...]”. Aqui se evidencia uma relação Eu/Outro/Mundo, em que ela cita o que seus alunos dizem sobre sua atuação (relação com o Outro) e demonstra autoconfiança (relação com o Eu) quando fala da diversificação de suas aulas ("Eu faço aula prática. Pego e levo para o laboratório, pra ver alguma coisa. Saio na cidade, e eles gostam disso" -, relação Eu/Mundo). Ela se preocupa com o aprendizado dos alunoa e os motivos que dificultam seu aprendizado, caracterizando sua relação com o Mundo. O cuidado com a vida pessoal doa alunos e com as atitudes docentes em sala de aula sinalizam uma forte relação com o Outro, depositado nos discentes.

Ao ser questionada sobre qual é a imagem que quer passar aos alunos, ela afirmou: "[...] De repente eu entendo o que eles têm. De repente eles não tão rendendo pra mim porque eles têm algum problema. Se eles têm algum problema, eu ajudo." Novamente, fica explicitada uma relação com o Outro, pois sente-se responsável em compreender as limitações do alunos e prestar-lhes auxílio. Apesar disso, ela sente diferenças entre os alunos que tinha no início da carreira e os atuais: "Vixi, água e vinho. Quando eu comecei a trabalhar, os alunos ouviam, faziam, prestavam atenção, entregavam trabalho no dia, estudavam para as avaliações, estudavam mesmo, na raça, viam, prestavam atenção na aula. [...] Hoje, você tem que se virar em 10 lá na frente pra chamar a atenção deles [...]”. Apesar de queixar-se dos alunos atuais, ela não mostra insatisfação com a carreira docente, em vez disso, assume postura diferenciada, como foi possível verificar quando afirmou realizar aulas práticas e também ao afirmar que precisa realizar esforços para conseguir a atenção dos estudantes. Isso indica uma relação Outro/Mundo, na busca em diversificar suas atitudes, apesar das diferenças entre os alunos.

Outro problema atual citado pela professora é a desmotivação dos colegas recém-formados: "[...] não têm experiência, não tentam pegar uma experiência, 
não perguntam pra ninguém [...] já vem desestimulados, já vem desmotivados”, ao contrário dela, que afirma ter assumido postura diferente: "[...] quando comecei a carreira, eu queria virar o mundo, queria fazer e acontecer [...] Alguns estão ali por causa do salário, claro, eu também estou ali por causa do salário, mas eu tenho que tentar fazer o meu salário ser de verdade. [...]”. Sua relação com a profissão é evidente, pois suas queixas dos professores com menor experiência advêm de sua trajetória e da importância que a carreira tem em sua vida, devido ao vínculo que mantém na relação com o Mundo.

Apesar de já ter tido problemas pessoais, não deixava isso mudar suas aulas ou sua atitude perante os alunos: "[...] eu já passei por uns problemas sérios. [...] Eu tive meus problemas, e tava lá na minha casa os meus problemas. Eu ia pra escola e tentava deixar do lado de fora [...]”. Assim, é possível ver que a professora não deposita nos alunos suas frustrações, visto que sua relação com o Outro/Mundo, mantém uma postura na profissão. Embora já tenha passado por um momento de crise em sua carreira, a entrevistada não teve vontade de abandonar a carreira: "Olha, eu já tive um ano [...] que eu tive problemas com a direção de escola [...] eu fiquei com vontade de sair daquela escola, não da minha carreira, não da minha profissão, mas sair da escola que eu tava."

Quanto ao que a manteve na carreira, a professora respondeu: "[...] Amor à profissão”, o que caracteriza uma forte relação com o Eu e com o Mundo. E quando questionada sobre os fatores que a estimulam ou não, evidencia-se a relação com o Outro, ela cita o aluno: "O aluno nota 10" e "os drogados". O aluno é o fator que a estimula ou não: “O aluno, porque pra mim é o aluno que estimula on não.” A relação com o Outro, depositado no aluno é essencial à sua motivação. Em função dos seus fortes vínculos com o Eu, com o Outro e com o Mundo, o salário não é um fator que a desestimule: "[...] O dinheiro dá pra viver. [...] me realizei profissionalmente."

Ela afirma gostar do ambiente de sala de aula, o que pode ser confirmado nestas falas: "Eu gosto é da sala de aula com os meus alunos. Então eu me sinto realizada na profissão." A professora se sente preparada pra ministrar aulas apesar das dificuldades que encontra: "Eu me sinto preparada. Tem horas que você tem desilusões na sala de aula. [...] eu acho assim, pra mim, é o que eu gosto. [...] Tem horas que eu fico frustrada? Fico. Toda profissão é assim. [...]”. E ao ser questionada sobre sua carreira atualmente, ela demonstra satisfação: "[...] não me arrependo. Não sei fazer outra coisa, é o que eu gosto. E eu gosto é de sala de aula." Além disso, a professora aponta suas emoções como essenciais para a realização da docência: “Tem que ter amor naquilo que vocêfar. Você tem que fazer bem feito." Apesar das dificuldades pelas quais passou no exercício da profissão, afirmou que se tivesse que optar por outra carreira, não abandonaria a profissão atual: “[...] hoje eu não queria trocar de profissão [...]”.

As relações Eu/Outro/Mundo da entrevistada estão fortemente ligadas à carreira docente. Sente-se realizada numa relação com o Eu, demonstrando satisfação com suas escolhas e segurança com o que faz: ("Eu gosto de fazer, de tentar fazer um trabalho bom e tentar fazer a diferença."). A entrevistada tem vínculo 
evidente com a licenciatura, logo, uma relação com o Mundo, ao afirmar sua preferência por estar trabalhando em uma sala de aula. E mesmo após decepções, centra seus esforços nos alunos, relação com o Outro que julga ter valor.

E um importante ponto a ser notado aqui, que fortalece o instrumento analítico utilizado, é o perfil subjetivo de desejo mantido e demonstrado pelas relações com o Eu, com o Outro e com o Mundo de cada sujeito, condicionantes da atitude e do comportamento que cada um apresenta para com a sua profissão. Como se vê, não está na "ausência de algo" a completa explicação para as atitudes e comportamentos dos professores frente a sua profissão, mas na característica do perfil de desejo que suas relações com o Eu, com o Outro e com o Mundo mantêm com o seu saber profissional. Pois, como se constata e como prova da força do referencial analítico utilizado, professores sob as mesmas circunstâncias escolares têm posturas distintas no que diz respeito ao seu saber profissional e suas relações com o saber profissional esclarecem de uma forma satisfatória a razão desse fenômeno. As relações com o Eu, com o Outro e com o Mundo dessa professora justificam e explicam sua estada na fase de Diversificação. Apesar das queixas, ela se mantém na carreira e procura mudar suas atitudes para com os alunos, em vez de abandonar a docência ou buscar nessa queixa uma justificativa para possíveis falhas.

\section{CONCLUSÕES}

O presente trabalho permitiu perceber que distintas relações com o Eu, com o Outro e com o Mundo mantidas pelos dois professores são capazes de fornecer uma compreensão para a permanência na carreira docente dos professores de Ciências estudados. A relação basicamente com o Eu, restrita à necessidade econômica do Professor 1, e uma relação forte de desejo profissional, caracterizada pelos vínculos mantidos com o Eu, com o Outro e com o Mundo da Professora 2 foram elementos centrais que justificam a persistência por um longo tempo no magistério. A perspectiva fundamentada nas relações com o saber profissional se mostrou além de um instrumento analítico singular, capaz de lançar um distinto olhar do que vem sendo até hoje apresentado na literatura da área com essa preocupação. Com isso, a leitura baseada no referencial de Charlot (2000) permite estender o nosso entendimento das fases específicas de Questionamento ou Diversificação de Huberman (1995) e que são relativas à permanência na carreira.

É importante ressaltar que o desenvolvimento profissional não é sempre único e contínuo, assim como descreveu Huberman (1995). Para alguns, esse processo pode parecer linear, mas para outros há patamares, regressões, becos sem saída, momentos de arranque e descontinuidades. E o fato de encontrarmos sequências não impede que outras pessoas nunca deixem de praticar a exploração, ou que nunca estabilizem, ou que se desestabilizem por razões de ordem das 
relações com o Eu, com o Outro e com o Mundo. É também necessário lembrar que a fase de Desinvestimento pode ocorrer já no meio da carreira, sem, no entanto, culminar na desistência da profissão e que um estudo baseado nas relações com o saber pode lançar luz sobre essa fase. A listagem de algumas relações com o saber profissional que mantêm os professores de Ciências aqui ilustrados na carreira, obviamente não restringe a existência de outras diversas relações, que justificam a trajetória pessoal e profissional de cada indivíduo. Assim, essas relações não podem e nem devem ser generalizadas, já que o perfil das relações com o Eu, com o Outro e com o Mundo é idiossincrático.

A resistência do professor na carreira é um objeto de estudo que pode contribuir para a criação de políticas públicas específicas que levem em consideração os anseios dos docentes e estimulem a resistência e a permanência desses profissionais na licenciatura. Dentro desse tema, o professor que tiver acesso a este trabalho pode vir a ter uma referência para se conscientizar das origens e do verdadeiro significado do seu próprio discurso, o que possibilita viabilizar a busca da sua superação dos discursos comuns da falta e da queixa. A tomada de consciência sobre o que os mantêm na carreira mostra-se coerente com a aplicação de políticas públicas para esses profissionais.

Esperamos que o referencial teórico apresentado contribua para um novo olhar, além de fornecer um ganho em profundidade para a compreensão da permanência dos professores de Ciências na carreira. O presente trabalho também vem a contribuir para percebermos que o uso do discurso da falta de recursos, de baixos salários e de condições adequadas ao trabalho, somadas às queixas quanto ao currículo, à política educacional e ao desinteresse dos alunos apenas mascaram as relações que temos com o Eu, com o Outro e com o Mundo. Dessa forma, acreditamos que as relações com o saber podem direcionar a uma reflexão do saber profissional que estão por trás de nossas falas e atitudes. 


\section{REFERÊNCIAS BIBLIOGRÁFICAS}

ASSIS, Alice; LABURÚ, Carlos Eduardo; SALVADEGO, Wanda Neves Cocco. A seleção de experimentos de Química pelo professor e o saber profissional. Revista Brasileira de Pesquisa em Educaşão em Ciências, Belo Horizonte, v. 9, n. 1, 2009.

BOGDAN, Roberto C; BIKLEN, Sari Knopp. Investigação qualitativa em Educação. São Paulo: Porto, 1994.

BRASIL. Lei n 10172, de 9 de janeiro de 2001. Aprova o Plano Nacional de Educação e dá outras providências. Disponível em:

<https://www.planalto.gov.br/ccivil_03/leis/leis_2001/110172.htm>. Acesso em: 3 jul. 2009.

BRASIL. Ministério da Educação. Secretaria de Educação Fundamental. Referenciais para formação de professores. Brasília: MEC, 2002.

CARVALHO, Anna M. Pessoa de; GIL-PÉREZ, Daniel. Formação de professores de Ciências. 5 ed. São Paulo: Cortez, 2006.

CHARLOT, Bernard. Da relação com o saber: elementos para uma teoria. Porto Alegre: Artmed, 2001.

FREIRE, Paulo. Professora sim, tia não: cartas a quem ousa ensinar. São Paulo: Olho d'água, 1997.

GARCÍA, Carlos Marcelo. A formação de professores: novas perspectivas baseadas na investigação sobre o pensamento do professor. In: NÓVOA, António (Coord.), et al. Os professores e a sua formaşão. Lisboa: Dom Quixote, 1997.

GONÇALVES, José Alberto M. A carreira das professoras do Ensino Primário. In: NÓVOA, A. (Org.). Vidas de professores. 2 ed. Porto: Porto Ed., 1995. cap. VI. p. 141-169.

HUBERMAN, Michaël. O ciclo de vida profissional dos professores. In: NÓVOA, A. (Org.). Vidas de professores. 2 ed. Porto: Porto Ed., 1995. cap. II. p. 31-61.

LABURÚ, Carlos Eduardo; BARROS, Marcelo Alves; KANBACH, Bruno Gusmão. A relação com o saber profissional do professor de Física e o fracasso da implementação de atividades experimentais no Ensino Médio. Revista Investigações em Ensino de Ciências, v. 12, n. 3, 2007.

MAMPRIM, Maria Imaculada; LABURÚ, Carlos Eduardo; BARROS, Marcelo Alves. La implementación o no de actividades experimentales em Biología em la enseñanza media y las relaciones con el saber profesional, basadas en una lectura de Charlot. Revista Electrónica de Enseñanza de las Ciencias, v. 7, n. 3, 2008. Disponível em:

<http://reec.uvigo.es/volumenes/volumen7/ART2_Vol7_N3.pdf>. Acesso em: 11 nov. 2009. NÓVOA, António. Formação de professores e profissão docente. In: NÓVOA, António (Coord.) et al. Os professores e a sua formação. Lisboa: Dom Quixote, 1997. p. 15-33.

. Os professores e as histórias de vida. In: NÓVOA, A. (Org.). Vidas de professores. 2 ed. Porto: Porto Ed., 1995.

OGO, Marcela Yaemi. A permanência na carreira do professor de Ciências: uma leitura baseada em Charlot. 2010. Dissertação (Mestrado em Ensino de Ciências e Educação Matemática) Universidade Estadual de Londrina, Londrina, Pr, 2010.

PASSOS, Julian da Silva. Identidade e formação de profissionais de Letras: a contribuição de Stuart Hall. Revista X, Curitiba, v. I, 2008.

PICHON-RIVIÈRE, E. A teoria do vinculo. Martins Fontes: São Paulo, 2000.

PIMENTA, Selma Garrido. Didática, didáticas específicas e formação de professores: construindo saberes. In: TIBALLI, Eliandra F. Arantes; CHAVES, Sandramara Matias (Org.). Concepcões e práticas em formação de professores: diferentes olhares. Rio de Janeiro: DP\&A, 2003. p. 49-56.

(Org.) et al. Saberes pedagógicos e atividade docente. 2 ed. São Paulo: Cortez, 2000.

SALVADEGO, Wanda Naves Cocco; LABURÚ, Carlos Eduardo. Uma análise das relações do saber profissional do professor do Ensino Médio com a atividade experimental no Ensino de Química. Revista Quimica Nova na Escola, v. 31, n. 3, ago. 2009.

STANO, Rita de Cássia M. T. Identidade do professor no envelhecimento. São Paulo: Cortez, 2001. TARDIF, Maurice. Saberes docentes e formacão profissional. Petrópolis: Vozes, 2002. 
Marcela Yaemi Ogo | Carlos Eduardo Laburú

Data de recebimento: $05 / 05 / 2010$

Data de aprovação: 20/01/2011

Data da versão final: $11 / 02 / 2011$ 